\title{
Acute-on-chronic effects of fatty acids on intestinal triacylglycerol-rich lipoprotein metabolism
}

\author{
Irene L. Black, Helen M. Roche*, Anne-Marie Tully and Michael J. Gibney \\ Unit of Nutrition, Department of Clinical Medicine, Trinity Health Sciences Centre, St. James's Hospital, Dublin 8, Ireland
}

(Received 11 October 2001 - Revised 11 July 2002 - Accepted 15 August 2002)

\begin{abstract}
Postprandial triacylglycerol (TAG) metabolism is an important metabolic state that has been associated with cardiovascular disease. The magnitude of the postprandial TAG response is determined by dietary fat composition, which alters intestinal and hepatic TAG-rich lipoprotein (TRL) metabolism. Caco-2 cell monolayers are morphologically and physiologically similar to the human intestinal enterocytes, hence they are a good model to study intestinal lipoprotein metabolism. To date only the acute effect of fatty acid composition on intestinal TRL metabolism in Caco-2 cells has been investigated. Little is known of the effect of habitual, or chronic, dietary fat composition on intestinal TRL metabolism. Using the Caco-2 cell model, the present study investigated the acute-on-chronic effect of fatty acid composition on TRL metabolism. Caco-2 cells were grown in the presence of 0.05 mM-palmitic acid (PA; $16: 0$ ), -oleic acid (OA; $18: 1 n-9)$,-eicosapentaenoic acid (EPA; $20: 5 n-3)$ or no fatty acid (control) for $19 \mathrm{~d}$, then one of four acute treatments (control (bovine serum albumin (BSA; $5 \mathrm{~g} / \mathrm{l})$ ) or BSA $(5 \mathrm{~g} / \mathrm{l}$ ) plus $0.5 \mathrm{~mm}-\mathrm{PA}$, -OA or -EPA) were administered for $22 \mathrm{~h}$. Significant acute $\times$ chronic interactions for the effect of fatty acid composition on cellular TAG:secreted de novo TAG, and cellular de novo TAG:de novo phospholipid were observed. Thus the effect of a fatty acid was determined by the duration of exposure to the fatty acid intervention. Acute PA treatment increased de novo TAG synthesis, but chronic PA supplementation did not. Acute and chronic OA treatments increased de novo TAG secretion. For EPA, chronic supplementation had the greatest effect on TAG synthesis and secretion. The acute-on-chronic effects of fatty acids on apolipoprotein B metabolism were relatively minor compared with the changes noted for TRL lipid composition. The present study shows that the Caco- 2 cell model is valuable for studying intestinal TRL metabolism and that fatty acids modulate this process, the nature of which can be determined by the length of exposure of the cell to the fatty acid.
\end{abstract}

Cardiovascular disease: Fatty acids: Lipid metabolism: Triacylglycerol: Caco-2 cells

Postprandial triacylglycerol (TAG) metabolism is an important physiological state that can be associated with cardiovascular disease, whereby the magnitude and duration of postprandial TAG concentrations are positively related to the pathogenesis and progression of atherosclerosis (Weintraub et al. 1988; Patsch et al. 1992; Karpe et al. 1994, 1997). The postprandial TAG response is determined by genetic, physiological and nutritional factors, the details of which have been extensively reviewed elsewhere (Roche \& Gibney, 1995, 2000). Both acute and chronic dietary fat composition is one of the most important nutritional determinants of postprandial TAG metabolism. In terms of the acute response, the greater the degree of unsaturation of the fatty acids presented in the test meal, the lower the postprandial TAG response (Zampelas et al. 1994). Chronic or habitual dietary fat composition also affects the magnitude of postprandial lipid metabolism. Dietary intervention studies show that the magnitude of the postprandial TAG response is greatest following a background saturated fatty acid (SFA) diet, less following an $n-6$ polyunsaturated fatty acid (PUFA)-rich diet and least following an $n-3$ PUFA-rich diet (Weintraub et al. 1988). Collaborative cross-cultural and dietary intervention studies by our research group show that the relative

\footnotetext{
Abbreviations: apo, apolipoprotein; BSA, bovine serum albumin; cB, non-secreted apolipoprotein B; cPL, non-secreted phospholipid; cTAG, non-secreted triacylglycerol; DPM, disintegrations/min; EPA, eicosapentaenoic acid; MUFA, monounsaturated fatty acid; OA, oleic acid; PA, palmitic acid; $\mathrm{P}_{\text {app}}$, permeability coefficient; PL, phospholipid; PUFA, polyunsaturated fatty acid; sB, secreted apolipoprotein B; SFA, saturated fatty acid; sPL, secreted phospholipid; sTAG, secreted triacylglycerol; TAG, triacylglycerol; TRL, triacylglycerol-rich lipoprotein.

* Corresponding author: Dr Helen M. Roche, fax +35314542043, email hmroche@tcd.ie
} 
proportion of monounsaturated fatty acids (MUFA) and SFA affects the nature of the postprandial response. Southern Europeans consuming a high-MUFA, low-SFA diet had significantly greater plasma TAG concentrations during the early postprandial state $(2-3 \mathrm{~h})$, which were then rapidly removed from the circulation, compared with Northern Europeans with a habitual low-MUFA, high-SFA diet, who were matched for age, gender and fasting lipid concentrations (Zampelas et al. 1998). In a subsequent dietary intervention trial, isoenergetic substitution of SFA for MUFA in the diet of Northern European males resulted in a greater increase in plasma TAG and TAG-rich lipoprotein (TRL) apolipoprotein (apo) B-48 levels during the early postprandial period (Roche et al. 1998). The significant alterations in plasma TAG and apo B-48 levels during the early postprandial phase suggested that dietary fatty acid composition altered gastrointestinal TRL metabolism.

The human colon carcinoma Caco- 2 cell line is an established model of the human small intestine because the cells spontaneously differentiate in culture into enterocytes and monolayers grown on permeable supports and are morphologically and physiologically similar to human intestinal enterocytes (Levy et al. 1995). The Caco-2 cell model allows investigation of the effects of dietary fat composition on intestinal TRL synthesis and secretion, that in turn contributes to postprandial TAG metabolism. Previous studies using Caco- 2 cells have investigated the acute effects of fatty acids on TRL TAG and apo B synthesis and secretion (Field et al. 1988; Moberly et al. 1990; Murthy et al. 1990; Ranheim et al. 1992; van Greevenbroek et al. 1995, 1996, 1998, 2000). These acute studies investigated the effect of one dose of a fatty acid given to cells in serum-free media for no longer than $24 \mathrm{~h}$. Such studies in the Caco-2 cell line have shown that oleic acid (OA; 18:1n-9) treatment induces a higher rate of TAG synthesis in Caco- 2 cells compared with linoleic acid $(18: 2 n-6)$ or palmitic acid (PA; 16:0) (Field et al. 1988). It was also shown that OA was the most efficient promoter of de novo TAG secretion followed by linoleic acid and PA (Field et al. 1988). Van Greevenbroek et al. (1996) confirmed that acute PA $(0.5 \mathrm{~mm})$ treatment reduces Caco-2 cell de novo TAG secretion compared with cells given either MUFA or $n-6$ PUFA treatment. Variation in the OA:PA ratios (final fatty acid concentration of $0.5 \mathrm{~mm}$ ) exposed to Caco- 2 cells also alters the secreted TRL:intermediate density lipoprotein and LDL-sized particles ratio by the cells (van Greevenbroek et al. 2000). The higher the OA:PA ratio administered to Caco- 2 cells, the greater the proportion of de novo TAG found in the TRL density fraction. Also an acute dose of eicosapentaenoic acid (EPA; $20: 5 n-3)(0 \cdot 25 \mathrm{mM})$ reduces de novo TAG synthesis and secretion, but had no effect on total TAG secretion from Caco-2 cells (Murthy et al. 1990).

To date, all in vitro studies have investigated the acute effect of fatty acids on Caco- 2 cell TRL metabolism as a model of intestinal lipoprotein metabolism. We known from human intervention studies that chronic or habitual dietary fats, including SFA (Zampelas et al. 1994), MUFA (Roche et al. 1998) and PUFA (Weintraub et al. 1988), modulate postprandial TAG metabolism. Whilst part of that effect is due to altered hepatic lipoprotein metabolism, it is becoming increasingly clear that intestinal lipoprotein synthesis and secretion is also important. Therefore the present experiment was designed to investigate the acute-on-chronic effects of fatty acid composition on intestinal TRL metabolism using the Caco- 2 cell model.

\section{Materials and methods}

Caco-2 cell culture

Adherent colon carcinoma cell line (Caco-2) was obtained from the European Collection of Animal Cell Cultures and was grown from passages 33 to 47 . Cells were grown in media (consisting of Dulbecco's Modified Eagle Medium (High Glucose, with Glutimax and $4500 \mathrm{mg} / 1$ D-glucose; GibcoBRL, Paisley, UK), fetal calf serum $(100 \mathrm{~g} / \mathrm{l} ;$ GibcoBRL), $1 \times$ sodium pyruvate (GibcoBRL) and gentimycin $(0.1 \mathrm{mg} / \mathrm{ml}$; GibcoBRL). Caco-2 cells were grown in $75 \mathrm{~cm}^{2}$ or $125 \mathrm{~cm}^{2}$ flasks (Falcon; Becton Dickinson, Oxford, UK) at $37^{\circ} \mathrm{C}$ in a humidified atmosphere of $5 \%(\mathrm{v} / \mathrm{v}) \mathrm{CO}_{2}$ until confluence was attained and were split by using trypsin-EDTA solution (GibcoBRL).

To investigate the acute-on-chronic effect of fatty acid supplementation on Caco-2 cell lipoprotein metabolism, the cells received a chronic fatty acid supplementation first, followed by an acute fatty acid treatment. For the chronic supplementation phase, the cells were seeded at a density of $3 \times 10^{5}$ cells per $24 \mathrm{~mm}$ polycarbonate transwells (growth area, $4.7 \mathrm{~cm}^{2}$; pore size, $0.4 \mu \mathrm{m}$; Costar, Cambridge, MA, USA). The cells were grown for $19 \mathrm{~d}$ in media only (controls), or in media supplemented with fatty acids (0.05 mM-PA, -OA or -EPA). Sodium hexadecanoic acid $\left(\mathrm{Na}^{+} \mathrm{PA}\right.$; Sigma-Aldrich Ireland Ltd, Tallaght, Dublin, Republic of Ireland), 9-octadecaenoic acid (OA; Sigma) and 5,8,11,14,17-eicosapentaenoic acid (EPA; Sigma) were stored at $-20^{\circ} \mathrm{C}$ in ethanol. Before use, OA and EPA had $\mathrm{Na}$ ions added to them to make them soluble in media (van Greevenbroek et al. 1995) and $\mathrm{Na}^{+} \mathrm{PA}, \mathrm{Na}^{+} \mathrm{OA}$ and $\mathrm{Na}^{+} \mathrm{EPA}$ were dried. A $30 \mathrm{~mm}$ solution of each fatty acid was made in deionised water and added to the cell culture media (containing fetal calf serum) in the apical compartment of the transwells. The basolateral compartment did not receive fatty acid supplementation. This was done to mimic the intestine where the apical surface of enterocytes is exposed to dietary fats. Cells were fed every $2 \mathrm{~d}$ with fresh media or media containing fatty acids during the $19 \mathrm{~d}$ chronic fatty acid supplementation period. At day 19 the acute-onchronic effect of fatty acid supplementation on de novo lipid synthesis was determined. First the cells were washed in $1 \times$ PBS (GibcoBRL). Then the acute fatty acid treatment was administered. Fetal calf serum-free media $(2.5 \mathrm{ml})$ was added to each basolateral compartment and fetal calf serum-free media $(1.5 \mathrm{ml})$ containing one of four acute treatments (bovine serum albumin (BSA; $5 \mathrm{~g} / \mathrm{l}$ )) only (control) or BSA ( $5 \mathrm{~g} / \mathrm{l})$ with $0.5 \mathrm{~mm}-\mathrm{PA}$, -OA or -EPA) was added to the apical compartment.

Before carrying out the main experiment, fatty acid-supplemented Caco- 2 cells were characterised to investigate whether fatty acid supplementation altered Caco- 2 cell 
growth and to determine how the fatty acids were assimilated into the lipid moieties of the supplemented cells compared with controls. Fatty acid supplementation with PA, OA and EPA at a concentration of $0.05 \mathrm{~mm}$ added to the apical compartment of the transwell did not alter cell growth and accumulated in the TAG and phospholipid (PL) fractions of the cells and hence these concentrations were used for the main experiments.

\section{Transepithelial electrical resistance measurements}

Transepithelial electrical resistance is a measure of resistance across monolayers and is used to assess monolayer development. The transepithelial electrical resistance of the Caco-2 epithelial cell monolayers was measured with an EVOM epithelial voltometer and STX2 electrode (World Precision Instruments, Sarasota, FL) every $2 \mathrm{~d}$ before changing the media. The electrode was sterilised for $20 \mathrm{~min}$ before use in $70 \%(\mathrm{v} / \mathrm{v})$ ethanol, and rinsed in media before measuring each transwell. A potential of $199 \mathrm{mV}$ was applied between the apical and basolateral compartments of the transwell and the resulting resistance $(\Omega)$ was measured $(0-1999 \Omega)$. At a concentration of 0.05 mM-fatty acid supplementation, transepithelial electrical resistance values were not significantly different between control and fatty acid-supplemented Caco- 2 cells.

\section{Viability assay}

The viability of cells that received acute $(0.5 \mathrm{~mm}$-fatty acid and BSA $(5 \mathrm{~g} / \mathrm{l})$ (Sigma) for $24 \mathrm{~h})$ and chronic exposure (media or $0.5 \mathrm{~mm} ; 0.25 \mathrm{~mm} ; 0.1 \mathrm{~mm}$ or $0.05 \mathrm{~mm}$-fatty acid for $17-21 \mathrm{~d}$ ) to each fatty acid treatment was assessed. Cells were seeded at a density of $4 \times 10^{4}$ cells/well, in a ninety-six-well microtitre plate (Falcon). Each experiment was repeated eight times. The media was changed every second day over the course of cell growth. A 3-(4,5dimethylthiazol-2-yl)-2,5-dephenyltetrazolium bromidethiazolyl blue (Sigma) solution $(5 \mathrm{mg} / \mathrm{ml})$ in $1 \times$ PBS (GibcoBRL) was made and stored at $4^{\circ} \mathrm{C}$. For experimentation, media or fatty acid treatment $(180 \mu \mathrm{l})$ was added to cells and cells were incubated for $24 \mathrm{~h}$. Subsequently, 3-4,5-dimethylthiazol-2-yl)-2,5-dephenyltetrazolium bromide-thiazolyl blue solution $(20 \mu \mathrm{l})$ was added to the media and the cells were incubated for an additional $4 \mathrm{~h}$ at $37^{\circ} \mathrm{C}$. SDS $(100 \mathrm{~g} / \mathrm{l})$ and $\mathrm{HCl}(0.01 \mathrm{M})$ were then added to the cells, which were then incubated overnight at $37^{\circ} \mathrm{C}$ before the absorbance was read at $\lambda=$ 490 and $\lambda=570 \mathrm{~nm}$ (Elisa Plate Reader; Dynatech MR5000 Microplate Reader; Dynex, Peterborough, Eaton, UK). Two-sample $t$ tests against the control were used to assess viability, with the null hypothesis that viability was not affected by supplementation. The null hypothesis was rejected if the viability of the cells was lower than $95 \%$ of the control. Chronic supplementation with $0.1 \mathrm{~mm}$ or $0.05 \mathrm{~mm}$ of any fatty acid had no effect on cell viability. Viability of cells was not affected by acute fatty acid treatment of $0.5 \mathrm{~mm}$ and BSA $(5 \mathrm{~g} / \mathrm{l})$ or of BSA ( $5 \mathrm{~g} / \mathrm{l})$ (control), for $24 \mathrm{~h}$.

\section{Proliferation assay}

The CellTiter 96 Aqueous Non-Radioactive Cell Proliferation Assay kit (Promega, Madison, WI, USA) was used to test the proliferation of cells under different fatty acid treatments. Each experiment was repeated eight times. Cells were seeded at $10^{5}$ cells/well in ninety-six-well microtitre plates (Falcon) and grown for $24 \mathrm{~h}$ in control media or media supplemented with chronic fatty acids $(0.1 \mathrm{~mm}$ and $0.05 \mathrm{~mm})$. The manufacturer's protocol was followed. Then 3-(4,5-dimethyl-2-yl)-5-(3-carboxymethoxyphenyl-2-(4-sulfophenyl)-2H-tetrazolium, inner salt-phenazine methosulfate solution $(20 \mu \mathrm{l})$ was added to each well and the cells were incubated for $90 \mathrm{~min}$ at $37^{\circ} \mathrm{C}$. The absorbance at $\lambda=490 \mathrm{~nm}$ was read using an ELISA plate reader (Dynatech MR5000 Microplate Reader; Dynex). Two-sample $t$ tests against the control were used to test for differences in the proliferation rate. The results showed that cells given either $0.1 \mathrm{mM}$ - or $0.05 \mathrm{mM}$-fatty acid proliferate at the same rate as the control cells.

\section{Translocation assay: paracellular and intracellular permeability}

The permeability of the Caco- 2 cell monolayers following the different fatty acid supplementations was measured using two radioactive marker molecules, $\left[{ }^{3} \mathrm{H}\right]$ proprananol (15-30 ci/mmol; Amersham Pharmacia, Amersham, Bucks, UK), a lipophilic intracellular marker, and $\left[{ }^{14} \mathrm{C}\right]$ mannitol (50-62 ci/mmol; Amersham Pharmacia), a paracellular marker, as previously described (Roche et al. 2001). Briefly, cells were seeded as for chronic supplementation phase and grown for either 6 or $14 \mathrm{~d}$ with or without the addition of PA, OA or EPA (0.1 mM and 0.05 mM). Experimentation ( $n$ 5) was carried out using Hank's balanced salt solution (GibcoBRL) at day 6 or 14 post-seeding in sixwell plates (Falcon). Both $\left[{ }^{3} \mathrm{H}\right]$ proprananol and $\left[{ }^{14} \mathrm{C}\right] \mathrm{man}-$ nitol, each emitting 150000 disintegrations/min (DPM), were added to the apical compartment of the transwell. Then the translocation of the intracellular and paracellular markers was assessed at 15, 30, 45, 60, 90 and $120 \mathrm{~min}$. Basolateral Hank's balanced salt solution (1 ml) was removed from each well of the six-well plates to vials containing $10 \mathrm{ml}$ scintillation fluid (Lumagel safe, Lumac LSC; Packard, Groningen, The Netherlands). DPM were counted for $10 \mathrm{~min}$ at radioactivity windows of 0.0 to $12 \cdot 0$ for $\left[{ }^{3} \mathrm{H}\right]$ proprananol and $12 \cdot 0$ to 156 for $\left[{ }^{14} \mathrm{C}\right]$ mannitol (TriCarb 2100Tr, Liquid Scintillation Analyzer; Packard). The apparent permeability coefficient $\left(\mathrm{P}_{\text {app }}\right)$ was calculated according to the equation:

$$
\mathrm{P}_{\mathrm{app}}(\mathrm{cm} \times \mathrm{sec})=(\mathrm{dQ} / \mathrm{dt}(\mathrm{s})) / \mathrm{A}\left(\mathrm{cm}^{2}\right) \times \mathrm{C}_{\mathrm{o}},
$$

where $\mathrm{dQ} / \mathrm{dt}$ is the slope of the graph of the DPM $v$. time in $\mathrm{s}, \mathrm{A}$ is the area of the transwell $\left(4.7 \mathrm{~cm}^{2}\right)$ and $\mathrm{C}_{\mathrm{o}}$ is the initial DPM (150000 DPM) added to the transwell. $\mathrm{P}_{\text {app }}$ values for fatty acid-supplemented cells were assessed and found to be similar to control cells for both the paracellular and intracellular markers. This suggests that fatty acid supplementation of $0.1 \mathrm{~mm}$ or $0.05 \mathrm{~mm}$ had no effect on tight-junction formation and lipid transport in Caco-2 cells. 


\section{Fatty acid compositional analysis}

The lipid compositions of cellular and secreted TAG and PL fractions were assessed following PA, OA and EPA supplementation. On day 19 post-seeding (the media being changed every $2 \mathrm{~d}$ ) the Caco- 2 cell basolateral media (approximately $3 \mathrm{ml}$ ) was transferred to a sterile $15 \mathrm{ml}$ tube (Falcon) and stored $\left(-80^{\circ} \mathrm{C}\right)$ before lipid isolation. Apical media was removed from the cells, which were washed in $1 \times$ PBS (GibcoBRL). Then $1 \mathrm{ml} 1 \times$ PBS (GibcoBRL) was added to the apical compartment of the transwell and the cells were scraped off the membranes and transferred to $1.5 \mathrm{ml}$ tubes (Starstead, Wexford, Republic of Ireland). The cells were centrifuged at $132000 \mathrm{rpm}$ for $2 \mathrm{~min}$ and the supernatant fraction was removed. The cells were re-suspended in $1 \mathrm{ml} 1 \times$ PBS and stored $\left(-80^{\circ} \mathrm{C}\right)$ until subsequent lipid isolation. The lipid in the basolateral media and cellular fraction was extracted using the Folch method, as previously described (Gibney \& Daly, 1994). The isolated lipids were stored at $-80^{\circ} \mathrm{C}$. The TAG and PL fractions of lipid in the basolateral media and cellular were isolated by TLC, as previously described (Roche \& Gibney, 1997), and stored $\left(-80^{\circ} \mathrm{C}\right)$. The basolateral lipids could not be visualised on the TLC plate and so cellular and basolateral lipid fractions isolated from each transwell were loaded beside each other on the TLC plate. This was done because it was observed that when Caco- 2 cells were supplemented with different fatty acids, the TAG fractions isolated from these cells would run at different rates. Methyl esters of fatty acids for GLC analysis were generated using the $\mathrm{BF}_{3}$ method (Shishehbor et al. 1998). The fatty acid composition of the TAG and PL fractions of the cells and basolateral medium were analysed using a Shinadzu GC-14A Series GLC (Mason Technologies, Dublin, Republic of Ireland) fitted with a BP 21 GC polar Al coated silica column (Scientific Glass Engineering Europe Ltd., Milton Keynes, Bucks., UK). The TAG and PL samples derived from the cells and basolateral medial were re-suspended in $80-100 \mu l$ hexane, of which $65-80 \mu l$ was injected onto the GC column at a 1:60 split ratio and analysed according to conditions described previously (Shishehbor et al. 1998). A diagram (Fig. 1) of the differences between cellular fatty acid composition in fatty acid-supplemented Caco- 2 cells $(0.05 \mathrm{mM})$ and control cells shows that supplementing Caco-2 cells with PA, OA and EPA altered cellular fatty acid composition in a fatty acid-specific manner. Investigation of fatty acid supplementation at concentrations of $0.5,0.25,0.1 \mathrm{~mm}$ as well as $0.05 \mathrm{~mm}$ showed that cellular fatty acid composition was altered in a dosedependent manner. PA supplementation increased cellular $16: 0$ levels and decreased $18: 1 n-9$ levels. OA supplementation led to an increase in cellular 18:1n-9 levels. EPA supplementation increased cellular 20:5n-3 levels and decreased $18: 1 n-9$ levels. These findings confirm the uptake of the chronic fatty acid supplements by Caco-2 cells.

\section{De novo triacylglycerol and phospholipid synthesis}

The acute-on-chronic effect of fatty acid supplementation on de novo lipid synthesis was determined in Caco-2 cells following $19 \mathrm{~d}$ of chronic fatty acid supplementation. The cells were washed in $1 \times$ PBS (GibcoBRL) and the acute fatty acid treatments were administered. Fetal calf serum-free media $(2.5 \mathrm{ml})$ was added to each basolateral compartment and fetal calf serum-free media $(1.5 \mathrm{ml})$ containing one of four acute treatments (BSA $(5 \mathrm{~g} / \mathrm{l})$ only (control) or BSA $(5 \mathrm{~g} / \mathrm{l})$ with $0.5 \mathrm{~mm}-\mathrm{PA}$, -OA or -EPA) was added to the apical compartment. Immediately, $13 \mu \mathrm{l}$ (400 ng, $1443000 \mathrm{DPM})$ of $\left[{ }^{14} \mathrm{C}\right]$ glycerol $(140-168 \mathrm{mCi} /$ mmol; Amersham Pharmacia) was added to each apical

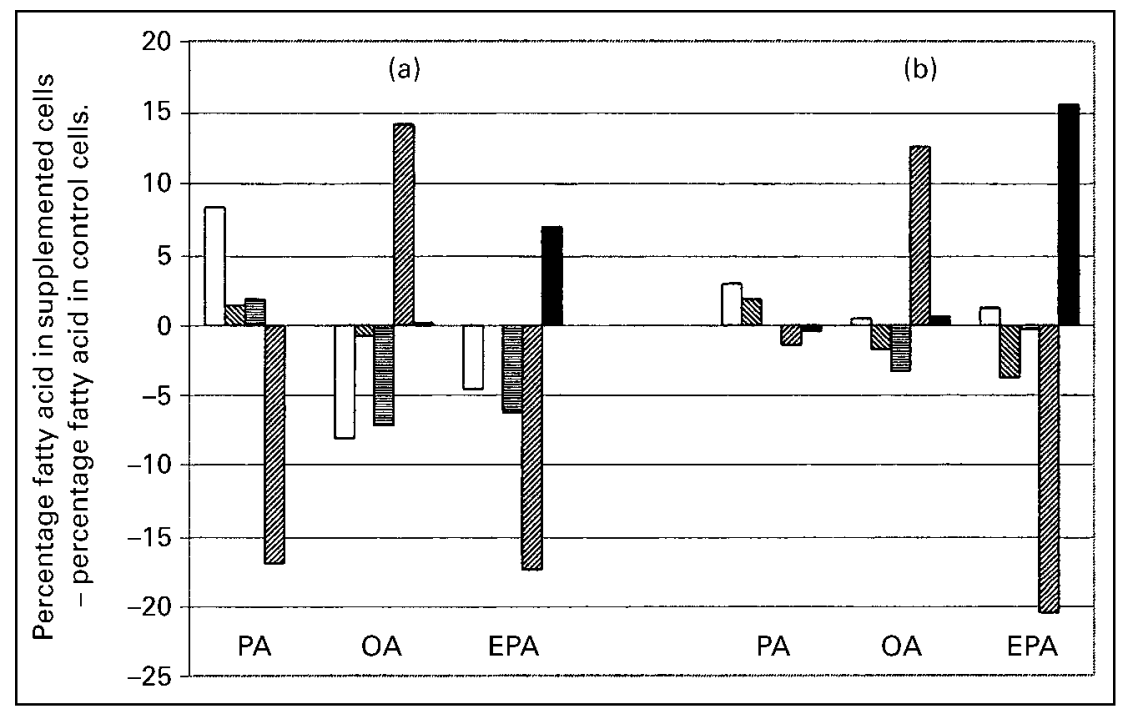

Fig. 1. Difference between cellular triacylglycerol (a) and phospholipid (b) compositions in Caco-2 cells after fatty acid supplementation $(0.05 \mathrm{~mm})$ with palmitic acid (PA), oleic acid (OA) or eicosapentaenoic acid (EPA) compared with Caco-2 cells not supplemented with fatty acids. $(\square), 16: 0 ;(\mathbb{\mathbb { V }}), 16: 1$; (目), $18: 0 ;(\mathbb{Q}), 18: 1 ;(\square), 20: 5 n-3$. 
compartment, and cells were incubated for $22 \mathrm{~h}$ at $37^{\circ} \mathrm{C}$. The basolateral media for total lipid determination was harvested into $15 \mathrm{ml}$ tubes (Falcon) and frozen immediately. Cells were washed in $1 \times$ PBS (GibcoBRL) and scraped into $1.5 \mathrm{ml}$ eppendorfs (Starstead). The cells were centrifuged at $13200 \mathrm{rpm}$ for $2 \mathrm{~min}$ and the supernatant fraction was removed. The cells were re-suspended in $1 \times$ PBS (GibcoBRL) and stored at $-80^{\circ} \mathrm{C}$ until lipid isolation. Lipids were isolated from the basolateral media and cellular fraction using the Folch method (Gibney \& Daly, 1994). The TAG and PL fractions from the basolateral media and cells were separated by TLC (Roche \& Gibney, 1997), the TAG and PL fractions were scraped into $10 \mathrm{ml}$ liquid scintillation fluid (Lumagel safe, Lumac.LSC; Packard) and counted for $10 \mathrm{~min}$ (TriCarb 2100Tr, Liquid Scintillation Analyzer; Packard).

\section{Immunoprecipitation and apolipoprotein B analysis}

The acute-on-chronic effect of fatty acid supplementation on de novo apo $\mathrm{B}$ synthesis was determined in Caco-2 cells following $19 \mathrm{~d}$ of chronic fatty acid supplementation. Acute fatty acid treatments were administered to Caco-2 cells as described earlier. Then $10 \mu \mathrm{l}$ (22 200000 DPM) of $\left[{ }^{35} \mathrm{~S}\right]$ methionine $(40-500 \mathrm{mCi} / \mathrm{mmol}$; Amersham Pharmacia) was added to each apical compartment and the cells were incubated for $22 \mathrm{~h}$ at $37^{\circ} \mathrm{C}$ (Murthy et al. 1998). The basolateral media was harvested into $15 \mathrm{ml}$ tubes (Falcon) and protease inhibitors were added (Leupeptin $(1 \mathrm{mg} / \mathrm{ml})$, Pepstatin $(1 \mathrm{mg} / \mathrm{ml})$, Aprotinin $(1 \mathrm{mg} / \mathrm{ml})$, phenylmethanesulfonyl fluoride $(10 \mathrm{mg} / \mathrm{ml})$ and Benzamidine $(1 \mathrm{mg} / \mathrm{ml})$; Sigma). The cells were washed in $1 \times$ PBS (GibcoBRL) $\left(4^{\circ} \mathrm{C}\right)$, then $200 \mu \mathrm{l}$ Boehringer Mannheim wash 1 (Protein A-Agarose protocol; Boehringer Mannheim $\mathrm{GmbH}$, Ingleheim, Germany) with protease inhibitors was added to the cells, which were scraped into eppendorf tubes (Starstead). Cells were centrifuged to remove cellular debris and the supernatant fraction was transferred to a new tube. Cellular and basolateral fractions were pre-cleared (removal of any other antibodies) using the Protein A-Agarose protocol (Boehringer Mannheim $\mathrm{GmbH}$ ), and anti-human apo B antibody (ICN, OH, USA) was added. The immunoprecipitation of apo B-48 and apo B-100 was carried out using the Protein A-agarose method (Boehringer Mannheim $\mathrm{GmbH}$ ) according to the manufacturer's instructions. The apo B-100 and apo B-48 isoforms were separated on $4 \%$ running, $2 \%$ stacking SDS-PAGE gels. The Prestained Protein Large Molecular Weight Ladder (GibcoBRL) was loaded on the SDS-PAGE gels along with the samples. The gels were run in $1 \times$ running

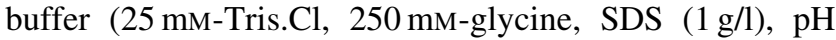
8.3) for approximately $90 \mathrm{~min}$ at $100 \mathrm{mV}$. Gels were dried on a gel dryer before autoradiography film (Hyperfilm; Amersham Pharmacia) was put on the gels. Films were developed after $2 \mathrm{~d}$. The quantity of both forms of apo B, apo B-100 and apo B-48 were measured using an instant imager (Instant Imager, Model A202401; Packard, Reading, Berks, UK). The apo B-100 (500 kDa) and apo B-48 $(230 \mathrm{kDa})$ proteins were identified by comparison with the apo B-100 (Sigma) and apo B-48 (internal laboratory standard) standards and the Prestained Large Molecular Weight Protein Ladder (GibcoBRL).

\section{Statistical analysis}

The objective of the present study was to examine the acute-on-chronic effects of fatty acid composition on Caco-2 cell TRL synthesis and secretion. The original data, the mean and standard error DPM values of the lipid analysis are presented in Table 1. To investigate de novo TAG, PL and apo $\mathrm{B}$ synthesis and secretion the following ratios were used as metabolic indicators of

Table 1. Disintegrations per minute obtained for lipid fractions* (Mean values with their standard errors)

\begin{tabular}{|c|c|c|c|c|c|c|c|c|c|}
\hline \multirow{2}{*}{$\begin{array}{l}\text { Lipid fraction counted... } \\
\text { Chronic treatment }\end{array}$} & \multirow[b]{2}{*}{ Acute treatment } & \multicolumn{2}{|c|}{ cTAG } & \multicolumn{2}{|c|}{ sTAG } & \multicolumn{2}{|c|}{ cPL } & \multicolumn{2}{|c|}{ sPL } \\
\hline & & Mean & SE & Mean & SE & Mean & SE & Mean & SE \\
\hline Control & BSA $(5 \mathrm{~g} / \mathrm{l})$ & 10056 & 937 & 516 & 40 & 25460 & 2787 & 448 & 203 \\
\hline Control & $\mathrm{PA}(0.5 \mathrm{~mm})+\mathrm{BSA}(5 \mathrm{~g} / \mathrm{l})$ & 45829 & 4087 & 4857 & 883 & 47161 & 7553 & 830 & 301 \\
\hline Control & $\mathrm{OA}(0.5 \mathrm{~mm})+\mathrm{BSA}(5 \mathrm{~g} / \mathrm{l})$ & 20436 & 551 & 6417 & 1226 & 39460 & 4607 & 889 & 324 \\
\hline Control & $\mathrm{EPA}(0.5 \mathrm{~mm})+\mathrm{BSA}(5 \mathrm{~g} / \mathrm{l})$ & 16019 & 4397 & 1068 & 274 & 40881 & 1776 & 909 & 191 \\
\hline PA $(0.05 \mathrm{~mm})$ & BSA $(5 \mathrm{~g} / \mathrm{l})$ & 9603 & 772 & 842 & 118 & 19355 & 1379 & 180 & 26 \\
\hline PA $(0.05 \mathrm{~mm})$ & $\mathrm{OA}(0.5 \mathrm{~mm})+\mathrm{BSA}(5 \mathrm{~g} / \mathrm{l})$ & 23533 & 1779 & 3870 & 241 & 24554 & 1305 & 359 & 24 \\
\hline PA (0.05 mm) & $\mathrm{EPA}(0.5 \mathrm{~mm})+\mathrm{BSA}(5 \mathrm{~g} / \mathrm{l})$ & 8718 & 1146 & 1237 & 326 & 26015 & 3912 & 437 & 169 \\
\hline $\mathrm{OA}(0.05 \mathrm{~mm})$ & BSA $(5 \mathrm{~g} / \mathrm{l})$ & 9992 & 882 & 778 & 53 & 20949 & 2251 & 143 & 14 \\
\hline $\mathrm{OA}(0.05 \mathrm{~mm})$ & $\mathrm{PA}(0.5 \mathrm{~mm})+\mathrm{BSA}(5 \mathrm{~g} / \mathrm{l})$ & 38687 & 2732 & 3137 & 465 & 28799 & 3247 & 455 & 70 \\
\hline $\mathrm{OA}(0.05 \mathrm{~mm})$ & $\mathrm{OA}(0.5 \mathrm{~mm})+\mathrm{BSA}(5 \mathrm{~g} / \mathrm{l})$ & 21768 & 2044 & 4588 & 270 & 25497 & 1368 & 377 & 25 \\
\hline $\mathrm{OA}(0.05 \mathrm{~mm})$ & $\mathrm{EPA}(0.5 \mathrm{~mm})+\mathrm{BSA}(5 \mathrm{~g} / \mathrm{l})$ & 9639 & 926 & 878 & 139 & 27385 & 4106 & 591 & 206 \\
\hline EPA (0.05 mm) & BSA (5 g/l) & 4059 & 655 & 400 & 74 & 18756 & 1950 & 165 & 40 \\
\hline EPA (0.05 mm) & $\mathrm{PA}(0.5 \mathrm{~mm})+\mathrm{BSA}(5 \mathrm{~g} / \mathrm{l})$ & 24886 & 1416 & 1609 & 177 & 38677 & 1610 & 404 & 82 \\
\hline
\end{tabular}

cTAG, non-secreted triacylglycerol; sTAG, secreted triacylglycerol; cPL, non-secreted phospholipids; sPL, secreted phospholipids; BSA, bovine serum albumin; PA, palmitic acid; OA, oleic acid; EPA, eicosapentaenoic acid.

${ }^{*}$ For details of treatments and procedures, see p. 662. 
intestinal lipid and apo B metabolism:non-secreted TAG:secreted TAG (cTAG:sTAG), cTAG:non-secreted PL (cTAG:cPL), sTAG:secreted PL (sTAG:sPL), nonsecreted apo B-100:secreted apo B-100 (cB100:sB100) and cB100:non-secreted apo B-48 (cB100:cB48). The acute-on-chronic effect of fatty acid composition on Caco-2 cell TAG and apo B metabolism was analysed by ANOVA (Data Desk 6.0; Data Descriptions Inc., New York, NY) for each variable in the cells that received chronic fatty acid supplementation followed by acute fatty acid treatment. Post hoc statistical analysis to identify the significant acute, chronic and acute $\times$ chronic effects of fatty acid composition was determined using protected least-significant difference tests. For the sake of clarity, the acute fatty acid intervention is referred to as a treatment, whilst the chronic fatty acid intervention is referred to as supplementation.

\section{Results}

\section{Cellular triacylglycerol:secreted triacylglycerol}

A significant acute $\times$ chronic interaction $(P=0.0236)$ was observed for cTAG:sTAG (Table 2). This demonstrates that the composition of the chronic fatty acid supplement determined the effect of the acute fatty acid treatments on cTAG:sTAG. The effect of chronic fatty acid supplementation alone is shown in the cells that received the acute BSA treatment. Chronic EPA supplementation reduced cTAG:sTAG compared with non-supplemented (control) cells $(P=0.004)$ following acute BSA treatment. Likewise following the acute EPA treatment, cTAG:sTAG was significantly $(P=0.015)$ reduced in the cell that had received chronic EPA supplementation. However, following acute PA treatment cTAG:sTAG was significantly increased when the cells had received chronic EPA supplementation compared with control supplemented cells $(P=0 \cdot 05)$. In all cases EPA supplementation decreased cellular de novo TAG synthesis by approximately 2 -fold compared with non-supplemented cells (Table 1). In addition, the acute PA treatment following chronic EPA supplementation reduced de novo TAG secretion (Table 1). In the cells that did not receive a chronic fatty acid supplement (controls), the acute effect of fatty acid treatment alone can be observed. Acute PA $(P=0.007)$ and OA $(P=0.0001)$ treatments significantly reduced cTAG:sTAG compared with chronic control cells that received the acute BSA treatments. When cells received chronic PA supplementation, the acute OA treatment significantly reduced $(P=0.03)$ cTAG:sTAG compared with acute BSA-treated cells. These effects were due to increased de novo TAG secretion (Table 1). Also the acute EPA treatment, following chronic PA supplementation, reduced cTAG:sTAG but this difference was only significantly different from the acute PA treatment $(P=0.023)$. This difference was due to lower cellular TAG levels in the acute EPA-treated cells (Table 1). Following chronic OA supplementation, acute OA treatment significantly reduced cTAG:sTAG compared with acute BSA $(P=0.006)$, PA $(P=0.003)$ and EPA $(P=0.014)$ treatments, by increasing de novo TAG secretion (Table 1). In contrast, chronic EPA supplementation caused acute PA treatment to significantly increase cTAG:sTAG compared with acute BSA $(P=0.029)$, OA $(P=0.001)$ and EPA $(P=0.014)$ treatments due to increased TAG synthesis following acute PA treatment (Table 1).

\section{Cellular triacylglycerol:cellular phospholipids}

A significant acute $\times$ chronic interaction $(P=0.0001)$ for cTAG:cPL (Table 3) shows that the acute response to a fatty acid treatment was affected by the composition of the chronic fatty acid supplement. The acute PA treatment significantly increased cTAG:cPL compared with the acute BSA $(P=0.000)$ and EPA treatments $(P<0 \cdot 001)$, irrespective of chronic fatty acid composition, which was due to increased de novo TAG synthesis over de novo PL synthesis. The magnitude of this increase in cTAG:cPL was affected by the composition of the chronic fatty acid supplement. Compared with the control cells that did not receive a chronic fatty acid supplement, chronic PA and OA supplementation before the acute PA treatment increased the cTAG:cPL values $(P=0.000$ and $P=0.001$, respectively), which was due to increased de novo TAG synthesis over de novo PL synthesis (Table 1). Caco-2 cells that received the acute OA treatment also had

Table 2. The effect of chronic fatty acid supplementation followed by acute fatty acid treatments on non-secreted triacylglycerol:secreted triacylglycerol*

(Mean values with their standard errors for four or five samples)

\begin{tabular}{|c|c|c|c|c|c|c|c|c|c|c|}
\hline $\begin{array}{l}\text { Acute treatment... } \\
\text { Chronic supplementation }\end{array}$ & \multicolumn{2}{|c|}{ BSA $(5 \mathrm{~g} / \mathrm{l})$} & \multicolumn{2}{|c|}{$\begin{array}{c}\mathrm{PA} \\
\underset{(0.5 \mathrm{~mm})+\mathrm{BSA}}{(5 \mathrm{l})}\end{array}$} & \multicolumn{2}{|c|}{$\begin{array}{c}\mathrm{OA} \\
(0.5 \mathrm{~mm})+ \\
\operatorname{BSA}(5 \mathrm{~g} / \mathrm{l})\end{array}$} & \multicolumn{2}{|c|}{$\begin{array}{c}\text { EPA } \\
(0.5 \mathrm{~mm})+\mathrm{BSA} \\
(5 \mathrm{~g} / \mathrm{l})\end{array}$} & \multicolumn{2}{|c|}{ ANOVA† } \\
\hline Control & $16 \cdot 99^{\mathrm{a} 1}$ & 2.68 & $8 \cdot 88^{\mathrm{bc} 1}$ & 0.85 & $3 \cdot 68^{b 1}$ & 0.66 & $14 \cdot 21^{\mathrm{ac} 1}$ & $5 \cdot 44$ & \multicolumn{2}{|c|}{$\mathrm{MSE}=14.05$} \\
\hline PA $(0.05 \mathrm{~mm})$ & $11 \cdot 76^{\mathrm{ab} 12}$ & 2.08 & $13 \cdot 83^{\mathrm{a} 12}$ & 1.65 & $5 \cdot 91^{\mathrm{c1}}$ & 0.93 & $7 \cdot 59^{\mathrm{bc} 2}$ & $2 \cdot 33$ & Acute & 0.0001 \\
\hline $\mathrm{OA}(0.05 \mathrm{~mm})$ & $12 \cdot 01^{\mathrm{a} 12}$ & 0.65 & $12 \cdot 7^{\mathrm{a} 12}$ & 0.67 & $4 \cdot 38^{b 1}$ & 0.56 & $11 \cdot 12^{\mathrm{a} 12}$ & $1 \cdot 14$ & Chronic & 0.4678 \\
\hline
\end{tabular}

BSA, bovine serum albumin; PA, palmitic acid; OA, oleic acid; EPA, eicosapentaenoic acid.

$a, b, c$ Mean values within a row with unlike superscript letters were significantly different (acute treatment effect) $(P<0.05)$.

${ }^{1,2}$ Mean values within a column with unlike superscript numbers were significantly different (chronic supplementation effect) $(P<0 \cdot 05)$.

${ }^{*}$ For details of treatments and procedures, see p. 662.

† Least-squared difference tests were used to identify the fatty acids responsible for acute $\times$ chronic interaction. 
Table 3. The effects of chronic fatty acid supplementations followed by acute fatty acid treatments on non-secreted triacylglycerol:nonsecreted phospholipids*

(Mean values with their standard errors for eight to ten samples)

\begin{tabular}{|c|c|c|c|c|c|c|c|c|c|c|}
\hline \multirow{2}{*}{$\begin{array}{l}\text { Acute treatment... } \\
\text { Chronic supplementation }\end{array}$} & \multicolumn{2}{|c|}{ BSA (5g/l) } & \multicolumn{2}{|c|}{$\begin{array}{c}\mathrm{PA} \\
(0.5 \mathrm{~mm})+\mathrm{BSA} \\
(5 \mathrm{~g} / \mathrm{l})\end{array}$} & \multicolumn{2}{|c|}{$\begin{array}{c}\mathrm{OA} \\
\underset{(0.5 \mathrm{~mm})+\mathrm{BSA}}{(5 \mathrm{~g} / \mathrm{l})}\end{array}$} & \multicolumn{2}{|c|}{$\begin{array}{c}\text { EPA } \\
(0.5 \mathrm{~mm})+\mathrm{BSA} \\
(5 \mathrm{~g} / \mathrm{l})\end{array}$} & \multicolumn{2}{|c|}{ ANOVA† } \\
\hline & Mean & SE & Mean & SE & Mean & SE & Mean & SE & Effect & $P$ \\
\hline Control & $0.401^{\mathrm{a} 1}$ & 0.026 & $1.099^{b 1}$ & 0.148 & $0.564^{\mathrm{a} 1}$ & 0.059 & $0.391^{\mathrm{a} 1}$ & 0.102 & $M S E=0.04$ & \\
\hline PA $(0.05 \mathrm{~mm})$ & $0.495^{\mathrm{a} 1}$ & 0.018 & $1.576^{\mathrm{c} 3}$ & 0.072 & $0.961^{\mathrm{b} 2}$ & 0.06 & $0.363^{\mathrm{a} 1}$ & 0.042 & Acute & 0.0001 \\
\hline $\mathrm{OA}(0.05 \mathrm{~mm})$ & $0.496^{\mathrm{a} 1}$ & 0.042 & $1.448^{\mathrm{c} 3}$ & $0 \cdot 16$ & $0 \cdot 86^{\mathrm{b} 2}$ & 0.086 & $0.394^{\mathrm{a} 1}$ & 0.052 & Chronic & 0.0001 \\
\hline EPA $(0.05 \mathrm{~mm})$ & $0.21^{\mathrm{a} 1}$ & 0.022 & $0.645^{\mathrm{b} 2}$ & 0.026 & $0.634^{\mathrm{b} 1}$ & 0.043 & $0 \cdot 283^{\mathrm{a} 1}$ & 0.042 & Acute $\times$ Chronic & 0.0001 \\
\hline
\end{tabular}

BSA, bovine serum albumin; PA, palmitic acid; OA oleic acid; EPA eicosapentaenoic acid.

a,b,cMean values within a row with unlike superscript letters were significantly different (acute treatment effect) $(P<0.05)$.

$1,2,3$ Mean values within a column with unlike superscript numbers were significantly different (chronic supplementation effect) $(P<0 \cdot 05)$.

${ }^{*}$ For details of treatments and procedures see p. 662

† Least-squared difference tests were used to identify the fatty acids responsible for acute $\times$ chronic interaction.

increased cTAG:cPL, but this was only significant in the cells that received chronic PA and OA supplementation compared with the control $(P=0.000$ and $P=0.001$, respectively); again this was due to increased de novo TAG synthesis (Table 1). In response to both the acute PA and acute OA treatments, cTAG:cPL was increased to a greater extent after chronic PA supplementation than after chronic OA supplementation; because acute PA treatment increased cellular de novo TAG levels more than acute OA treatment (Table 1). In cells that received chronic EPA supplementation before the acute PA treatment, the cTAG:cPL values were significantly decreased compared with the acute BSA $(P=0.000)$ treatment because of increased cellular de novo PL production compared with de novo TAG synthesis (Table 1 ).

\section{Secreted triacylglycerol:secreted phospholipids}

Although no significant acute-on-chronic interaction $(P=0.344)$ was observed for sTAG:sPL, both significant chronic $(P=0.002)$ and acute $(P=0.0001)$ effects were observed (Table 4). Post hoc tests showed that chronic PA and OA supplementation increased sTAG:sPL compared with the control $(P=0.03$ and $P=0.02$, respectively) and chronic EPA-supplemented cells $(P=0.002$ and $P=0 \cdot 001$, respectively). This difference was due to less secreted de novo PL (Table 1). The significant effect of acute fatty acid treatments on STAG:sPL was due to fatty acid-specific alterations in de novo TAG and PL secretion. The acute PA and OA treatments increased sTAG:sPL compared with the acute control BSA-treated cells $(P=0.001$ and $P=0.000$, respectively) by increasing secreted de novo TAG levels (Table 1). This increase in de novo TAG secretion levels was greater following the mean acute OA treatment compared with the mean acute PA treatment $(P=0 \cdot 000)$. In contrast, the acute EPA treatment decreased sTAG:sPL compared with BSA-treated cells $(P=0.05)$, which was due to increased de novo PL secretion (Table 1) following the mean acute EPA treatment.

\section{Cellular apolipoprotein B-100:secreted apolipoprotein B-100 and cellular apolipoprotein B-100:cellular apolipoprotein $B-48$}

No significant effect of fatty acid supplementation, treatment or interaction on cB100:sB100 or cB100:cB48 was observed in the present study (data not shown).

\section{Discussion}

The important finding of the present study is that the composition of fatty acids presented as either an acute treatment $(<24 \mathrm{~h})$ or a chronic supplement $(19 \mathrm{~d})$ had a significant effect on intestinally derived TRL metabolism. Whilst these studies have been conducted in the Caco-2 cell model, they provide important information in terms of understanding how habitual (chronic) dietary fat composition determines the postprandial TAG response to acute test meals. The present study showed that a fatty acid could have a different effect on TRL metabolism depending on whether it is presented as an acute treatment or a chronic supplement. The results of the present study suggest that acute PA treatment and OA treatment were associated with an increase in cellular de novo TAG levels (cTAG:cPL). Cellular de novo TAG levels were increased by approximately 4-fold following acute PA treatment and 2-fold following acute OA treatment compared with acute BSA treatment, and were augmented when the acute treatments were preceded by chronic PA or OA supplementation. These data agree and extend those of van Greevenbroek et al. (1996), who showed that acute PA treatment also increased cellular TAG levels in Caco-2 cells. Also in hepatoma G2 cells acute PA treatment increased cellular TAG levels, compared with OA (Arrol et al. 2000). It is important to note that Caco-2 cells preferentially synthesise TAG rather than PL following PA exposure; this effect was attributed to increased utilisation of diacylglycerol to synthesis for TAG rather than PL (Trotter \& Storch, 1993).

As in previous studies (Field et al. 1988; van Greevenbroek et al. 1996) acute exposure to OA was associated with increased de novo TAG secretion (cTAG:sTAG and sTAG:sPL). Acute OA exposure to Caco-2 cells has been 
shown to increase de novo TAG secretion compared with controls (van Greevenbroek et al. 1996) and have higher de novo TAG secretion levels than acute PA or linoleic acid treatments (Field et al. 1988). The present study suggests that acute rather than chronic OA intervention has the greatest effect on de novo TAG secretion, although chronic OA supplementation was associated with increased de novo TAG secretion following the acute BSA and OA treatments. In terms of explaining the effect of $\mathrm{OA}$ on de novo TAG secretion, van Greevenbroek et al. (1998) hypothesised that OA was a better substrate than PA for the microsomal triacylglycerol transfer protein complex, resulting in large TAG-rich chylomicrons being secreted more quickly from the Caco-2 cells. Field et al. (1988) showed that acute OA treatment $(0.25 \mathrm{~mm})$ increased de novo TAG levels in TRL secreted by Caco- 2 cells. Also van Greevenbroek et al. (2000) demonstrated that TAG synthesised after acute OA treatment was assembled into TRL particles, whereas TAG synthesised after acute PA treatments was assembled in intermediate-density lipoprotein and LDL particles. Therefore it was hypothesised that in man a test meal rich in unsaturated fatty acid might form large chylomicrons that can be cleared rapidly from the circulation. In contrast, an SFA meal might form small chylomicrons that are secreted slowly by the intestinal enterocyte and are not cleared quickly from the circulation, thereby prolonging the postprandial lipid response (van Greevenbroek et al. 2000). Indeed the Caco-2 cell studies suggest concurrence with human trials that showed that habitual consumption of an OA-rich diet caused a very rapid rise in plasma TRL during the early postprandial phase, which were cleared efficiently from the circulation (Roche et al. 1998; Zampelas et al. 1998).

In the case of EPA, chronic fatty acid supplementation rather than acute EPA treatment resulted in significant effects on cTAG:sTAG and cTAG:cPL. Chronic exposure to EPA was associated with a 2 -fold reduction in cellular de novo TAG levels (cTAG:sTAG). A previous study showed that acute $(0.25 \mathrm{~mm})$ EPA exposure $(4 \mathrm{~h})$ significantly reduced de novo TAG synthesis and secretion in Caco-2 cells (Murthy et al. 1990). Conversely, Ranheim et al. (1992) demonstrated that acute $(0.6 \mathrm{~mm})$ EPA treatment $(<24 \mathrm{~h})$ stimulated de novo TAG synthesis and secretion, an effect that was similar to that of acute OA treatment. Our study extends this information, suggesting that chronic EPA supplementation may reduce intestinal de novo TAG synthesis. The results of the present study highlight that the concentration and duration of EPA intervention may explain divergent results between the previously published acute studies. Chronic EPA exposure was found to increase cellular de novo $\mathrm{PL}$ levels (cTAG:cPL) and acute or chronic EPA supplementation increased de novo PL secretion (sTAG:sPL). This may be due to acute EPA treatment inhibiting diacylglycerol acyl transferase activity thus reducing the competition for the PL synthesis pathway (Ranheim et al. 1992). In human subjects chronic $n-3$ PUFA supplementation is an effective hypotriacylglycerolaemic agent (Roche \& Gibney, 1996), which is largely attributable to reduced hepatic TAG synthesis and secretion (Harris et al. 1990). However, the present study suggests that chronic EPA may also modulate 
intestinal TAG metabolism by reducing cellular de novo TAG levels and by increasing PL synthesis due to inhibition of diacylglycerol acyl transferase activity.

In conclusion our study shows that the Caco- 2 cell model is a suitable model to investigate the acute-onchronic effects of fatty acid composition on intestinal TRL metabolism. The results show that particularly with regard to OA the Caco- 2 cell model concurs with human studies. The study also highlights that fatty acids can have different effects depending upon whether they are presented in the short (acute treatment) or long (chronic supplementation) term.

\section{References}

Arrol S, Mackness MI \& Durrington PN (2000) The effects of fatty acids on apolipoprotein B secretion by human hepatoma cells (HepG2). Atherosclerosis 150, 255-264.

Field FJ, Albright E \& Mathur SN (1988) Regulation of triglyceride-rich lipoprotein secretion by fatty acids in Caco-2 cells. Journal of Lipid Research 29, 1427-1437.

Gibney MJ \& Daly E (1994) The incorporation of n-3 polyunsaturated fatty acids into plasma lipid and lipoprotein fractions in the postprandial phase in healthy volunteers. European Journal of Clinical Nutrition 48, 866-872.

Harris WS, Connor WE, Illingworth DR, Rothrock DW \& Foster DM (1990) Effects of fish oil on VLDL kinetics in humans. Journal of Lipid Research 31, 1549-1558.

Karpe F, Olivecrona T, Hamsten A \& Hultin M (1997) Chylomicron remnant turnover in humans: evidence for margination of chylomicrons and poor conversion of larger to smaller chylomicron remnants. Journal of Lipid Research 38, 949-961.

Karpe F, Steiner G, Uffelman K, Olivercrona T \& Hamsten A (1994) Postprandial lipoproteins and progression of coronary atherosclerosis. Atherosclerosis 106, 83-97.

Levy E, Mehran M \& Seidman E (1995) Caco-2 cells as a model for intestinal lipoprotein synthesis and secretion. FASEB Journal 9, 626-635.

Moberly JB, Cole TG, Alpers DH \& Schonfeld G (1990) Oleic acid stimulation of apolipoprotein B secretion from HepG2 and Caco-2 cells occurs post-transcriptional. Biochimica et Biophysica Acta 1042, 70-80.

Murthy S, Albright E, Mathur SN \& Field FJ (1990) Effect of eicosapentaenoic acid on triacylglycerol transport in Caco-2 cells. Biochimica et Biophysica Acta 1045, 147-155.

Murthy S, Born E, Mathur S \& Field FJ (1998) 13-Hydroxy octadecadienoic acid (13-HODE) inhibits triacylglycerol-rich lipoprotein secretion by Caco-2 cells. Journal of Lipid Research 39, 1254-1262.

Patsch JR, Miesenbock G, Hopferwieser T, Muhlberger V, Knapp E, Dunn JK, Gotto AM \& Patsch W (1992) Relation of triglyceride metabolism and coronary artery disease. Arteriosclerosis and Thrombosis 12, 1336-1345.

Ranheim T, Gedde-Dahl A, Rustan AC \& Drevon CA (1992) Influence of eicosapentaenoic acid (20:5, n-3) on secretion of lipoproteins in Caco-2 cells. Journal of Lipid Research 33, $1281-1293$.
Roche HM \& Gibney MJ (1995) Postprandial triacylglycerolaemia - Nutritional Implications. Progress in Lipid Research 34, 249-266.

Roche HM \& Gibney MJ (1996) Postprandial triacylglycerolaemia: The effect of a low-fat diet with and without fish oil supplementation. European Journal of Clinical Nutrition 50, 617-624.

Roche HM \& Gibney MJ (1997) Postprandial coagulation factor VII activity: the effect of monounsaturated fatty acids. British Journal of Nutrition 77, 537-549.

Roche HM \& Gibney MJ (2000) The effect of long-chain n-3 PUFA on fasting and postprandial triacylglycerol metabolism. American Journal of Clinical Nutrition 71, 232-237.

Roche HM, Terres AM, Black IL, Gibney MJ \& Kelleher D (2001) Fatty acids and epithelial permeability: effect of conjugated linoleic acid in Caco-2 cells. Gut 48, 797-802.

Roche HM, Zampelas A, Jackson KG, Williams CM \& Gibney MJ (1998) The effect of test meal monounsaturated fatty acid:saturated fatty acid ratio on postprandial lipid metabolism. British Journal of Nutrition 79, 419-424.

Shishehbor F, Roche HM \& Gibney MJ (1998) The effect of acute carbohydrate load on the monophasic or biphasic nature of the postprandial lipaemic response of acute fat ingestion in human subjects. British Journal of Nutrition 80, 411-418.

Trotter PJ \& Storch J (1993) Fatty acid esterification during differentiation of the human intestinal cell line Caco-2. Journal of Biological Chemistry 268, 10017-10023.

van Greevenbroek MMJ, Erkelens DW \& de Bruin TWA (2000) Caco-2 cells secrete two independent classes of lipoproteins with distinct density: effect of the ratio of unsaturated to saturated fatty acid. Atherosclerosis 149, 25-31.

van Greevenbroek MMJ, Robertus-Tenissen MG, Erkelens DW \& de Bruin TWA (1998) Participation of the microsomal triglyceride transfer protein in lipoprotein assembly in Caco-2 cells: interaction with saturated and unsaturated dietary fatty acids. Journal of Lipid Research 39, 173-185.

van Greevenbroek MMJ, van Meer G, Erkelens DW \& de Bruin TWA (1996) Effects of saturated, mono-, and polyunsaturated fatty acids on the secretion of apoB containing lipoproteins by Caco-2 cells. Atherosclerosis 121, 139-150.

van Greevenbroek MMJ, Voorhout WF, Erkelens DW, van Meer G \& de Bruin TWA (1995) Palmitic acid and linoleic acid metabolism in Caco-2 cells: different triglyceride synthesis and lipoprotein secretion. Journal of Lipid Research 36, 13-24.

Weintraub MS, Grosskopf I, Rassin T, Miller H, Charach G, Rotmensch HH, Liron M, Rubinstein A \& Iaina A (1996) Clearance of chylomicron remnants in normolipidemic patients with coronary artery disease: case control study over three years. British Medical Journal 312, 936-939.

Zampelas A, Murphy M, Morgan LM \& Williams CM (1994) Postprandial lipoprotein lipase, insulin and gastric inhibitory polypeptide responses to test meals of different fatty acid composition: comparison of saturated, n- 6 and n-3 polyunsaturated fatty acids. European Journal of Clinical Nutrition 48, 849-858.

Zampelas A, Roche H, Kapsokefalou M, Knapper JME, Jackson KG, Pentaris E, Tornatis M, Hatzis C, Gibney MJ, Kafatos A, Gould BJ, Wright J \& Williams CM (1998) Differences in postprandial lipaemic response between Northern and Southern Europeans. Atherosclerosis 139, 83-93. 